\title{
The Change of Ultrasonic Transmission Velocity by Wood Decay ${ }^{1}$
}

\author{
Won-Joung Hwang ${ }^{2 \dagger} \cdot$ Hyun-Mi Lee ${ }^{2} \cdot$ Young-Ran Park ${ }^{2} \cdot$ Dong-Heub Lee ${ }^{2}$
}

\begin{abstract}
The deterioration in wood by the brown-rot fungus (Fomitopsispalustris) and the white-rot fungus (Trametesversicolor) were measured using ultrasonic velocity. Those were used for the decay exposure and 4 wood species of wood as the test specimens, Pinusdensiflora, Larixkaempferi, Pinuskoraiensis and Pinusrigida, were chosen with both the brown- and white-rot culture petridish during 12 weeks. After 12 weeks, the decrease rate of ultrasonic velocity was measured at 10 $\sim 15 \%$. In both brown- and white-rot exposure experiments, P. rigida showed significant decrease in ultrasonic velocity $(20 \%)$, L. kaempferi on the other hand did not show decrease in ultrasonic velocity. After the fungal exposure experiment, the inside of specimens was investigated by computer tomography $(\mathrm{C} / \mathrm{T})$. After $\mathrm{C} / \mathrm{T}$ investigation, bending tests were performed.
\end{abstract}

Keywords : Brown-rot fungus, White-rot fungus, Ultrasonic velocity, Computer tomography, Deterioration

\section{INTRODUCTION}

There are many problems affecting wood in timber architecture and in wooden cultural properties. These are caused by deterioration so that the performance is reduced due to the biological and non-biological factors. The study on timber architecture and historic timber architecture and deterioration is in progress. Kim et al. (2007) suggested that a pillar of historic timber architecture tends to be susceptible to deterioration and there are many examples of decay of various types of wooden parts in the environment around us. Kim et al. (2003) reported that

1 Received March 21, 2013; Accepted March 19, 2014

2 Korea Forest Research Institute

† Corresponding author : Won-Joung Hwang (e-mail: wonjoung@forest.go.kr) in deterioration evaluation of column members of ancient architecture through non-destructive inspection, deterioration of pillars at the section adjacent to the land and at the top of the upper part. Son et al. (2004) estimated the extent of decay of a Korean palace by nondestructive evaluation (NDE). Deterioration of the wood threatens a building's durability and internal stability.

Before assessing soundness of wood before it is used consideration of the systematic and historical importance of the wood is required and the method of measuring its internal state with avoiding direct destruction of wood is necessary. Following these requirements among the methods of evaluating wood soundness, the study of 
NDE using ultrasonic velocity in wood is being developed.

Lee et al. (2003), who investigated ultrasonic transmission route in wood, if ultrasonic cannot directly be transmitted by a defect in wood, it may be delivered by the primary reflection in the opposite side.

Park et al. (2008) tried to detect artificial flaws in wood using ultrasonic passing time. It is reported that there is a relationship between a location of the ultrasonic detector and the direction of fracture. Furthermore, to detect internal deterioration of wood, an artificial defect is made and ultrasonic velocity is measured. The result showed that the larger the size of a defect, the less the ultrasonic velocity (Saeed K. et al., 2009).

Lee et al. (2008) investigated on how brownrot fungus in wood is develops through measurement of mass loss rate, mechanical property and ultrasonic velocity with samples that have been exposed to brown-rot fungus in the wood The current study investigated the change in ultrasonic transmission velocity caused by the decay period and the change in ultrasonic transmission velocity in decayed specimens using ultrasonic transmission velocity about the absence of decay that is artificially produced through ultrasonic measuring instrument, Wood Pole Tester.

\section{MATERIALS AND METHOD}

\subsection{Fungal Culture}

Fomitopsispalustris and Trametesversicolor were a specimen size of is $2 \times 2 \times 30(\mathrm{~cm})$. The test specimens were Pinusdensiflora, Larixleptolepis, Pinuskoraiensis and Pinusrigida. By taking heartwood and sapwood samples from each species

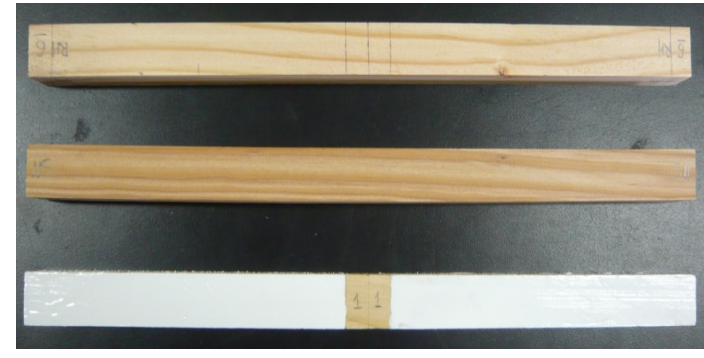

Fig. 1. The type of specimens.

of trees, atotal of eight test specimens was used in this study. A Wood Pole Tester (PROCEQ, CH/PILODYN, 6J), (77 kHz) was employed to measure the velocity of propagation of ultra sonic waves (Fig. 1). Computed tomography was undertaken using a TSX-0001A, (TOSHIBA corp), located in Korean Forest Research Institute (KFRI), where it is employed to measure bending test of wood.

\subsection{Experiment Method}

\subsubsection{Preparation of Test Specimens}

To find out the change in velocity of transmission of ultrasonic waves through wood caused by wood rot-fungieach test specimen $(2 \times 2 \times 30$ (cm)) was taken from the heartwood and sapwood of the different wood species (Fig. 1). The first condition is to make the space where it is both right and left side off $1 \mathrm{~cm}$ from the center of the length direction of test specimens. It is to protect the space from penetrating decaying rot-fungi when epoxy resin is sealed in the marked space (HT1, ST1). For the second condition, the method inoculating decaying rotfungi without epoxy resin sealed in the test specimens were employed (HT2, ST2). Finally, a control group of wood specimens which had not been inoculated with wood rot fungi was included. 


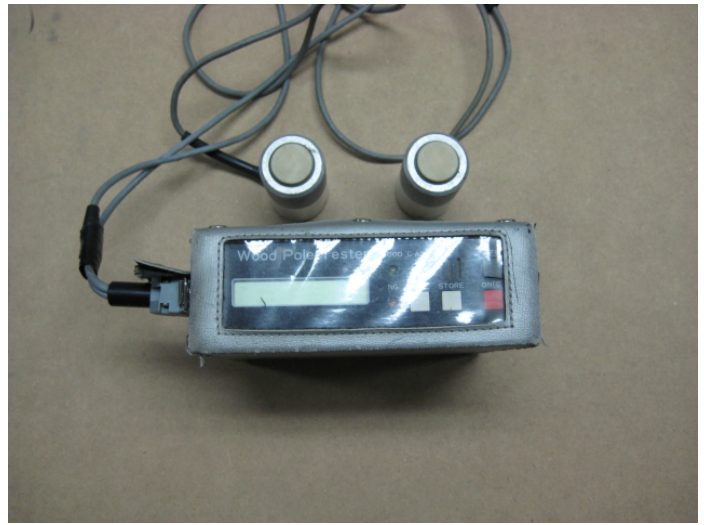

Fig. 2. Wood Pole tester.

\subsubsection{Measuring the Velocity of Propagation of Ultra Sonic Waves}

Measuring the velocity of propagation of ultrasonic waves was conducted by measuring the change in the velocity of propagation of ultra sonic waves by rot-fungi inside wood at every 7 days from a week when the wood rot-fungi were infected by the Wood Pole Tester (77 kHz) (Fig. 2).

\subsubsection{Experimental Construction}

After pouring and solidifying 2\% agar(which is without nutrition) with pressurization and sterilization in schale with $90 \sim 100$ diameter and $15 \mathrm{~mm}$ height, MRS agar is made including glucose $2.5 \%$, peptone $0.5 \%$, malt extract $1.0 \%$, potassium dehydrogen phosphate $0.3 \%$ and magnesium sulfate $0.2 \%$.

By positioning in the schalecentre of the length direction of a specimen, a mycelium was allowed to grow from the specimen's centre. Sterile water was added to the specimen as required. To protect the specimen from exterior fungi, test specimens were cultivated for 12 weeks in the sealed plastic bags, at a temperature of $26 \pm 2{ }^{\circ} \mathrm{C}$ and relative humidity greater than $70 \%$ (Fig. 3).

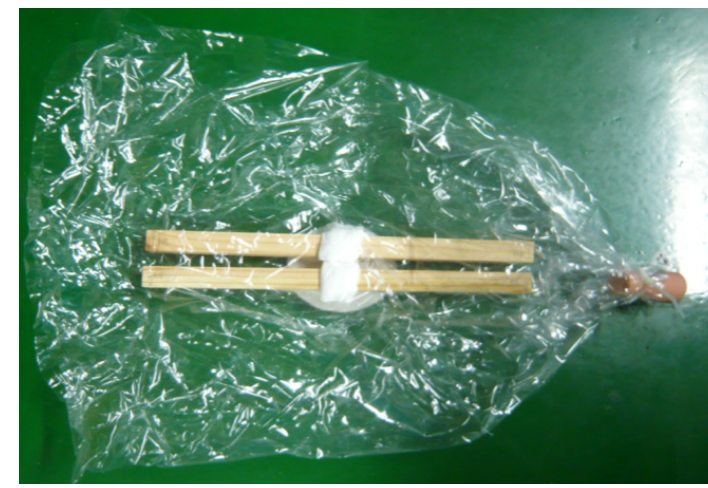

Fig. 3. Specimens under fungal exposure test.

\subsubsection{Computed Tomography}

After the experiment on decay exposure, to investigate the internal shape of wood was computed tomography bya TSX-0001A with X-Rays for 5 seconds at $120 \mathrm{kV}, 110 \mathrm{~mA}$ and set at 10 $\mathrm{mm}$ for intervals.

\section{RESULTS AND DISCUSSION}

\subsection{Change in Ultrasonic Velocity}

\subsubsection{Influence of $F$. palustris}

In the case of $P$. densiflora, ultrasonic velocity in wood at the early stage was 4881.65 $(\mathrm{m} / \mathrm{s})$ for the heartwood and $4609.43(\mathrm{~m} / \mathrm{s})$ for the sapwood and after 12 weeks it was recorded at $4026.50(\mathrm{~m} / \mathrm{s})$ for the mean of heartwood and $4286.15(\mathrm{~m} / \mathrm{s})$ for that of sapwood, respectively. From this result, heartwood of $P$. densiflora decreased by $17.51 \%$ and sapwood by $7.01 \%$.

For $P$. koraiensis, ultrasonic velocity in wood at the early stage was measured $4369.89(\mathrm{~m} / \mathrm{s})$ for the heartwood and $4466.01(\mathrm{~m} / \mathrm{s})$ for the sapwood and after 12 weeks it became 3891.82 $(\mathrm{m} / \mathrm{s})$ for the mean of heartwood and 4047.77 $(\mathrm{m} / \mathrm{s})$ for that of sapwood, indicating a decrease in $10.94 \%$ for heartwood and $9.36 \%$ for sap- 


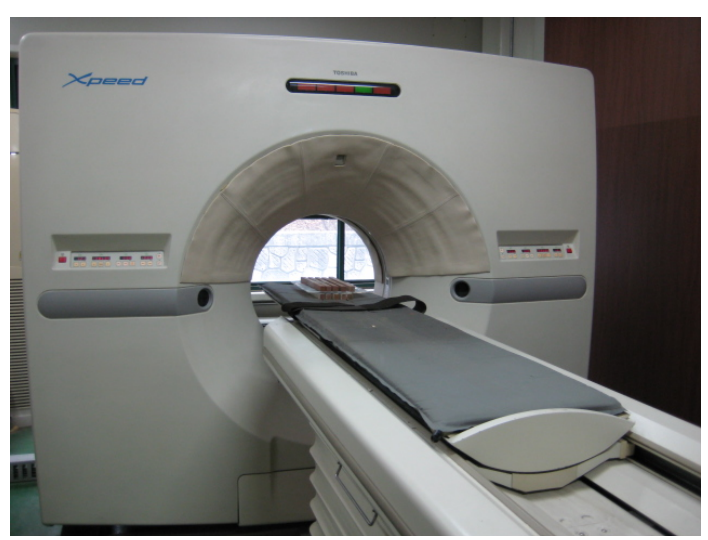

Fig. 4. Computed tomography.

wood compared with both means at the early stage, respectively (Fig. 4). Therefore the change in ultrasonic velocity in decayed heartwood changed more than for sapwood.

\subsubsection{Impact of $T$. versicolor}

Fig. 5 shows the relationship between F. pal-
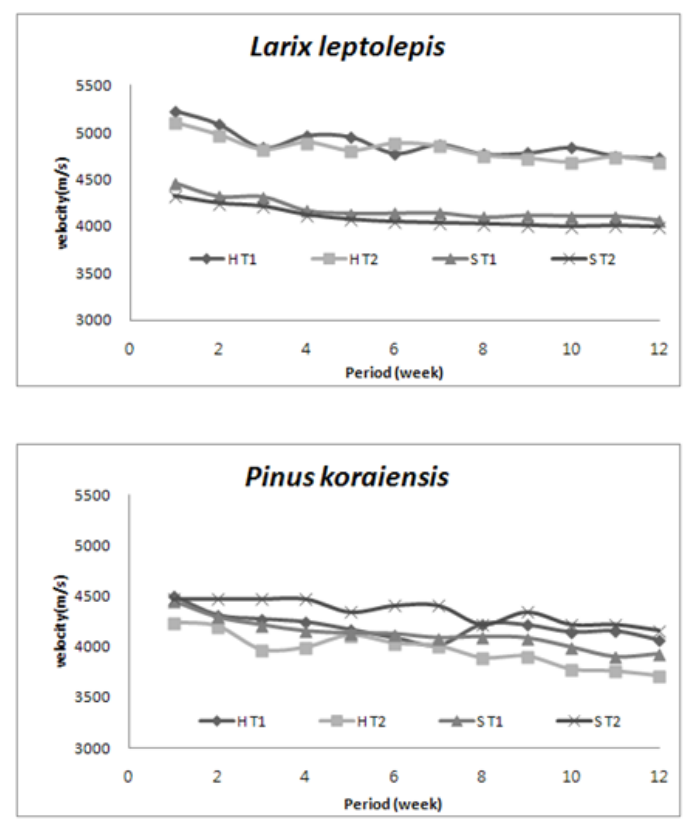

ustris exposure time and ultrasonic velocity.

Fig. 5 indicating the change in ultrasonic velocity in wood caused by T.versicolor. One week after inoculation, for P.densiflora, the average of the heartwood's ultrasonic velocity was 4459.57 $(\mathrm{m} / \mathrm{s})$ and that of sapwood's was $5137.58(\mathrm{~m} / \mathrm{s})$. After 12 weeks, the mean recordings for heartwood and sapwood average were $3880.31(\mathrm{~m} / \mathrm{s})$ and $4766.70(\mathrm{~m} / \mathrm{s})$ respectively.

In L.kaempferi, one week after inoculation, the heartwood mean of ultrasonic velocity was $4670.53(\mathrm{~m} / \mathrm{s})$ and the sapwood mean of that was $5057.41(\mathrm{~m} / \mathrm{s})$. After 12 weeks, the each average of heartwood and sapwood was 4018.61 $(\mathrm{m} / \mathrm{s})$ and $4690.55(\mathrm{~m} / \mathrm{s})$.

In the case of P.koraiensis, while mean ultrasonic velocity in wood at the early stage was $4812.75(\mathrm{~m} / \mathrm{s})$ for the heartwood average and $5147.29(\mathrm{~m} / \mathrm{s})$ for the sapwood average, after 12 weeks mean ultrasonic velocity in wood for the
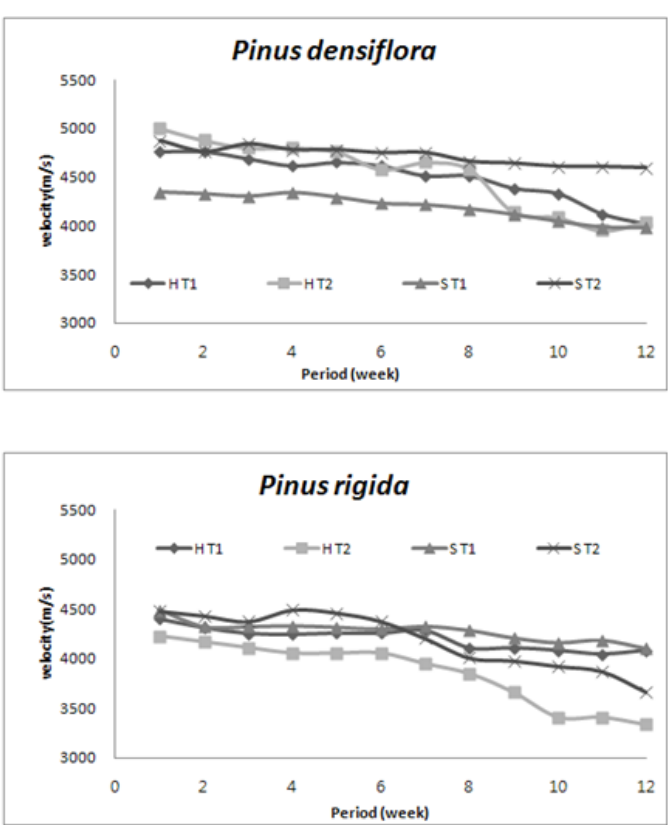

Fig. 5. Relationship between fungal exposure time and ultrasonic velocity (F.palustris). 

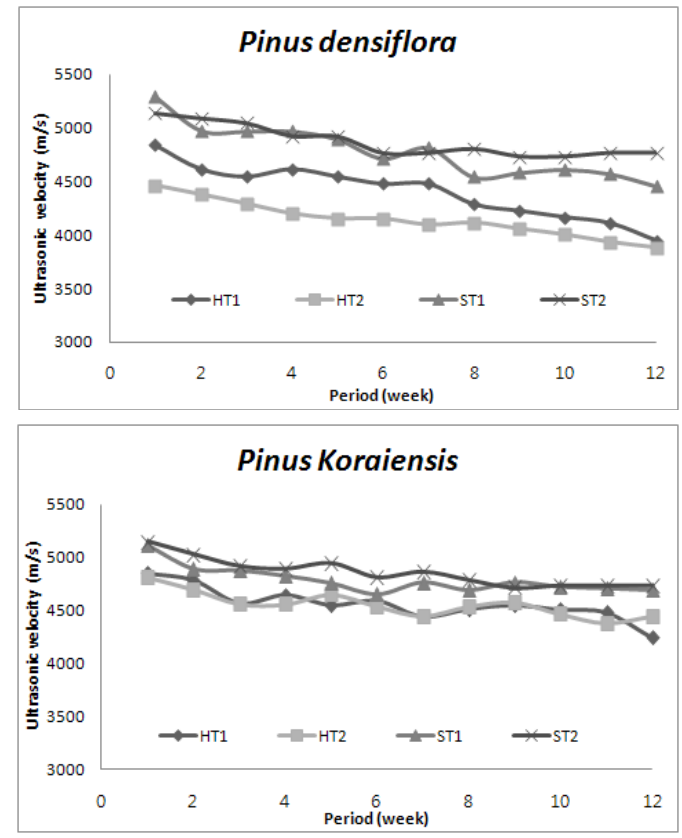
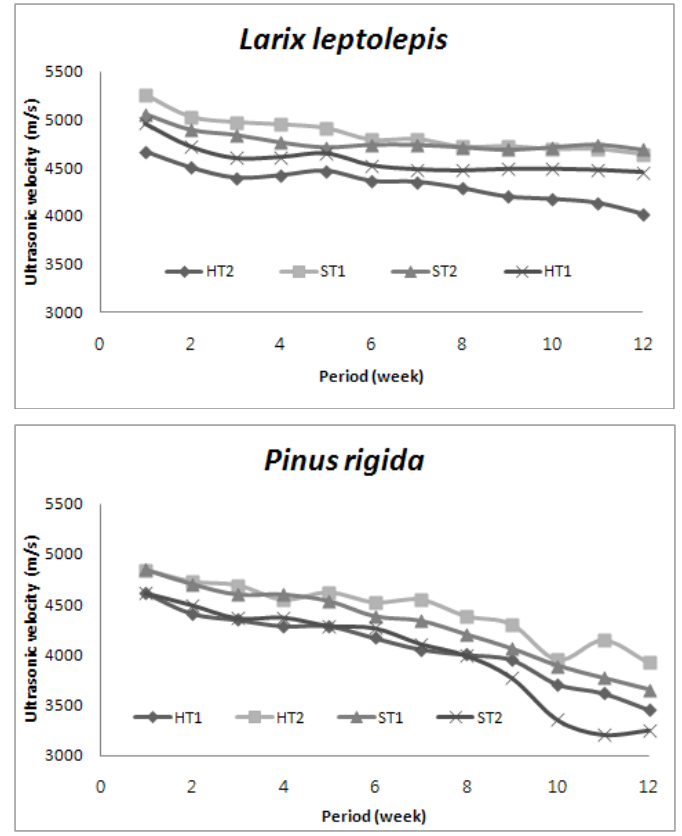

Fig. 6. Relationship between fungal exposure time and ultrasonic velocity (T.versicolor).

heartwood and sapwood mean was 4444.44 $(\mathrm{m} / \mathrm{s})$ and $4737.10(\mathrm{~m} / \mathrm{s})$.

In P.rigida, one week after inoculation, the heartwood was $4839.98(\mathrm{~m} / \mathrm{s})$ and the sapwood $4614.77(\mathrm{~m} / \mathrm{s})$ and after 12 weeks, both were measured in $3919.90(\mathrm{~m} / \mathrm{s})$ and $3248.20(\mathrm{~m} / \mathrm{s})$, respectively (Fig. 6).

\subsubsection{Change Rate of Ultrasonic Velocity}

Following exposure to the brown-rot fungus exposure comparison of ultrasonic velocity for two different periods (before and after inoculation), the change rate of ultrasonic velocity for each specimen indicated a decrease of $19.19 \%$ (P.densiflora's sapwood), 8.27\% (L.kaempferi's sapwood), 13.95\% (P.koraiensis's sapwood) and 21.11\% (P.rigida's sapwood). Among 4 specimens, the rate of change in ultrasonic velocity for P.rigida's sapwood was the most significant.
For T.versiclorthe ultrasonic velocity for the two different periods the rate of change in ultrasonic velocity for each specimen was $12.98 \%$ (P.densiflora's sapwood), 13.95\% (L.kaempferi's sapwood), 7.65\% (P.koraiensis's sapwood) and $19 \%$ (P.rigida's sapwood). Therefore for the 4 specimens, the rate of change for P.rigida's sapwood was again the most significant (Fig. 7).

Following decay F.palustris and T.versicolor over 12 weeks, computer tomography $(\mathrm{C} / \mathrm{T})$ was conducted. Fig. 7 shows the result of $\mathrm{C} / \mathrm{T}$ following decay exposure experiment. It is classified by positioning that Type 2 was put above Type 1 and plastic plate is set in the middle.

Son et al. (2004) found that in the decay test the larger decrease in wood mass caused by the decay then the slower the ultrasonic velocity. Furthermore the longer the wood exposure times the slower the ultrasonic velocity and there is a 

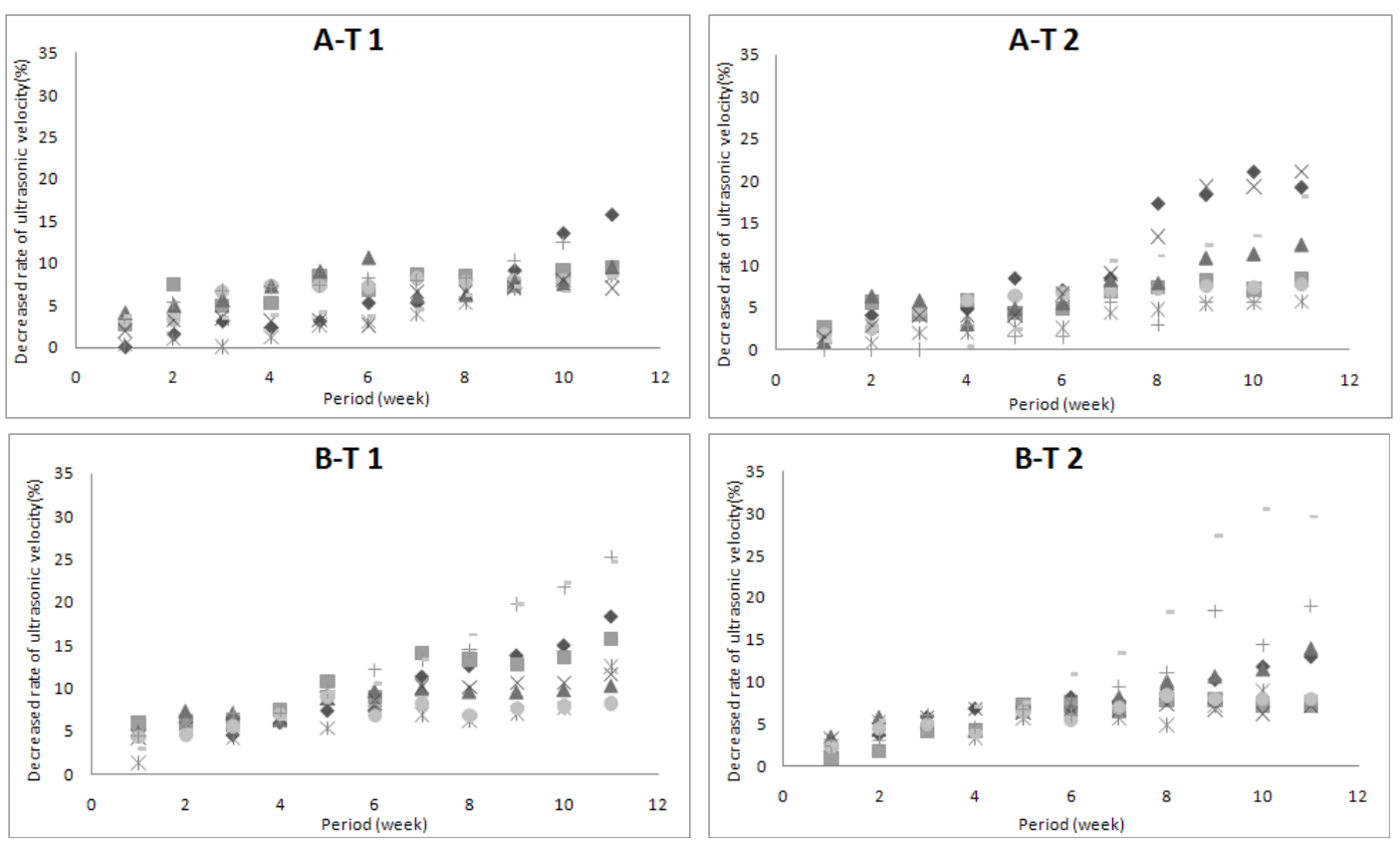

P. densiflora heart wood * P. densiflora sap wood

L. leptolepis heart wood

L. leptolepis sap wood

- $P$. koraiensis heart wood $+P$. koraiensis sap wood X P. rigida heart wood $-P$. rigida sap wood

Fig. 7. Relationship between fungal exposure time and decreased rate of ultrasonic velocity (A: F. palustris, B: T. versicolor).

difference in the extent of the decay and the rate of change in the ultrasonic velocity depending on the properties of each specimen property. Lee et al. (2008) reported on loss rate of mass and ultrasonic velocity through the test specimen $(10 \times 3 \times 10)$ that had been decayed by 2 types of brown-rot fungus. It was reported that at the early stage, the decay detection by measurement of ultrasonic velocity was possible and whereas qualitative evaluation was possible quantitative evaluation was unsatisfactory. Furthermore during 8 weeks of decay activity intensity capacity fell $80 \%$ and ultrasonic velocity decreased by around $30 \%$. Compared with the findings of Lee et al. (2008), the current experimental procedure used larger test specimens $(2 \times 2 \times 30)$ and a longer incubation period (12 weeks). Considering the size of the test specimens and the difference between types of wood, the results of decrease in the rate of ultrasonic velocity were similar to those published by Lee et al. (2008).

\subsection{Computer Tomography $(\mathrm{C} / \mathrm{T})$}

After the test specimens had been exposed to the decay fungi during 12 weeks period the internal conditions of the wood samples were investigated using computer tomography. In the test specimen of constant thickness and high density the decrease in X-ray energy was higher than that of the test specimen with low density. Therefore, the brightness of a film is high due to decreasing the sensitivity of the X-ray film. 

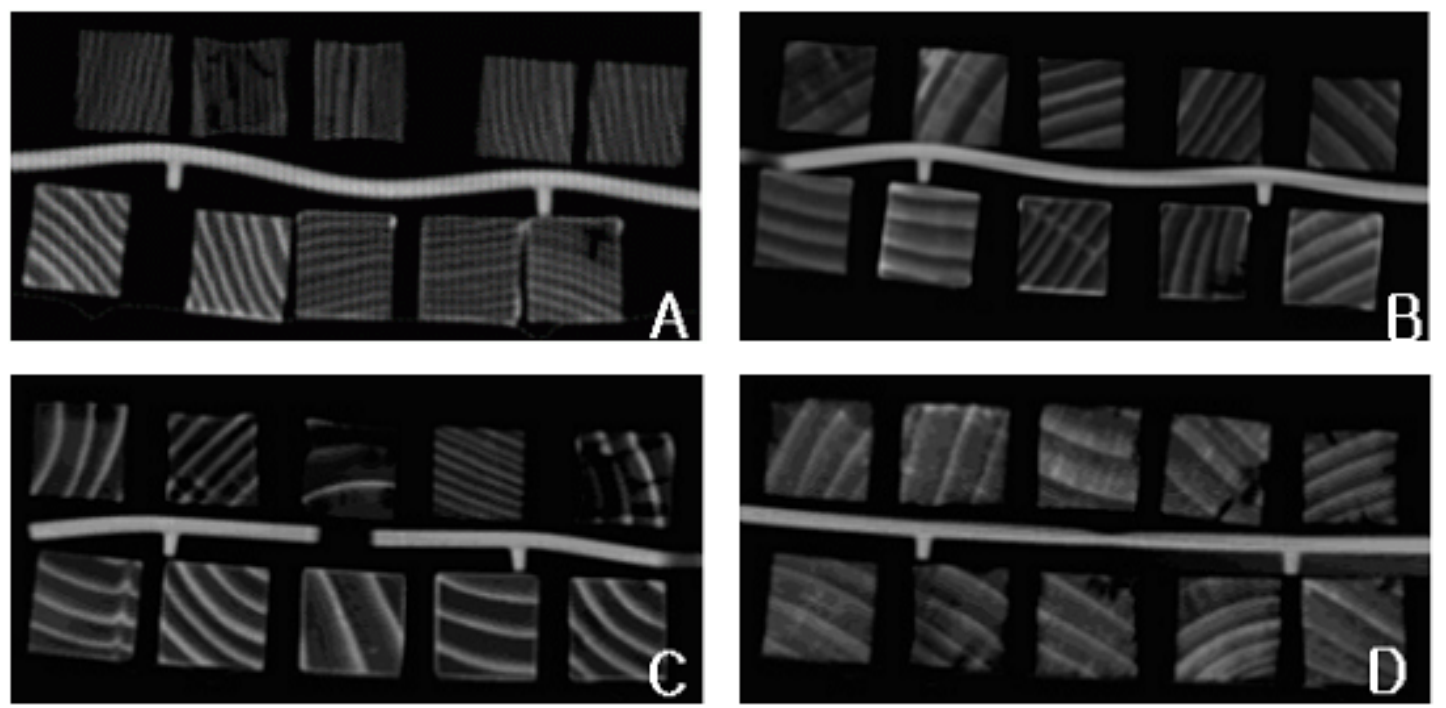

Fig. 8. CT images of specimens after fungal exposure test (A: P.densiflora B: P.koraiensis C: P.densiflora D: P.koraiensis) (A, B : decayed by $F$. palustris C,D : decayed by $T$. versicolor).

The greater the extent of the decay is, the lower the brightness is in the test specimen performed by $\mathrm{C} / \mathrm{T}$ (Fig. 8). As Kim et al. (2006) reported that the brightness in the edge of the test specimen is strongly observed and it is thought that the phenomenon results from higher the X-ray intensity reaching a film and the higher X-ray intensity the greater the brightness of a film.

\section{CONCLUSION}

This study using 4 different wood types which were separated into heartwood and sapwood was undertaken to assess the extent of deterioration and the change in ultrasonic velocity in the inside of wood following the decay period from brown-rot and white-rot fungi.

The result showed that there is a significant decrease in ultrasonic velocity at the early stage of decay. Results for the 4 types of wood used indicated that the deterioration caused by the brown-rot fungus in P.rigida (heartwood $21.11 \%$, sapwood $18.09 \%$ ) resulted in the largest changeL.kaempferi, the least change in ultrasonic velocity. Moreover, comparing heartwood and sapwood, heartwood decrease rate was higher than for sapwood.

Deterioration caused by the white-rot fungus was greatest in P.rigida (heartwood 19.00\%, sapwood $29.61 \%$ ). Like the brown-rot fungus the least change in the decrease in ultrasonic velocity was found to be for L.kaempferi. Except for P.rigida the remainder of the test specimens decrease in ultrasonic velocity was higher inheartwood was higher than in sapwood.

From this study, in artificially produced decay, qualitative evaluation is proved to be possible but additional research for quantitative evaluation is required 


\section{REFERENCES}

1. Kim, Y. S, J. H. Yoon, H. Y. Kang, and S. J. Park. 2007. Deterioration and Preservation Technique of Wooden Cultural Properties (Part. I )Biodeterioration of Wooden Round Columns, Janggeongpanjeon, Built in 15 century- Journal of the Korean Wood Science and Technology. 35(1): $51 \sim 63$.

2. Kim, Y. S. and S. M. Han. 2007. Deterioration and Preservation Technique of Wooden Cultural Properties (Part. II)-Biodeterioration of Square Post to Support Wooden Printing Blocks Shelves, Janggengpanjeon. Journal of the Korean Wood Science and Technology. 35(1): 64 72.

3. Korean Standards Association. 2004. Method of bending test for wood. KS F 2208.

4. Lee, J. J., G. M. Kim, and M. S. Bae. 2003. Transmission Process for Ultrasonic Wave in Wood. Journal of the Korean Wood Science and Technology. 31(2): 31 37.

5. Lee, S. J., G. H. Kim, and J. J. Lee. 2008. Effect of brown-rotted wood on mechanical properties and ultrasonic velocity. Journal of the Korean Wood Science and Technology. 36(5): 24 32.

6. Park, J. C. and S. I. Hong. 2008. Determination of Localized Defects in Wood by the Transfer Time of Ultrasonic Waves. Journal of the Korean Wood Science and Technology. 36(1): 61 68.

7. Ross, R. J., L. A. Soltis, and P. Otton. 1998. Role of nondestructive evaluation in the inspection and repair of the USS Constitution. Journal of Preservation Technology. 27(2): 145 152.

8. Ross, R. J., J. C. Ward, and A. TenWolde. 1992. Identifying bacterially infected Oak by stress wave nondestructive evaluation. Res Pap. FPLRP-512. Madison, WI: U.S. Department of Agriculture, Forest Service, Forest Products Laboratory. $6 \mathrm{p}$.

9. Schad, K. C., D. L. Schmoldt, and R. J. Ross. 1996. Nondestructive methods for detecting defects in softwood logs. Res Pap.FPL-RP-546. Madison, WL-U.S. Department of Agriculture, Forest Service, Forest Products Laboratory.13 p.

10. Saeed, Kazemi-Najafi., A. Shabafan, and G. Ebrahimi. 2009. Intermal decay in standing beech trees using ultrasonic velocity measurement. European Journal of Forest Ressearch. 128: 345 350.

11. Son, D. W. and D. H. Lee. 2004. Wood Decay Detection by Non-destructive Methods. Journal of the Korean Wood Science and Technology. 32(4): $74 \sim 81$.

12. Son, D. W. and D. H. Lee. 2008. Evaluation on Termite Damage of the Traditional Wooden Building by Non-destructive Methods. Journal of the Korean Wood Science and Technology. 36(1): $21 \sim 29$.

13. Wang, X., R. J. Ross, J. A. Mattson, J. W. Forsman, E.A. Geske, and M. A. Wehr. 2002. Nondestructive evaluation techniques for assessing modulus of elasticity and stiffness of small-diameter logs. Forest Prod. J. 52(2): 79 $\sim 85$. 